\title{
JMP syndrome
}

INSERM

\section{Source}

INSERM. (1999). Orphanet: an online rare disease and orphan drug data base. IMP syndrome. ORPHA:324999

Joint contractures, muscle atrophy, microcytic anemia and panniculitis-induced lipodystrophy (JMP) syndrome is a rare autoinflammatory disorder belong ing to the proteasome disability syndrome (see this term) group and characterized by sclerodermic skin with the presence of erythematous lesions, joint contractures, generalized or partial lipodystrophy, muscle atrophy and short stature. 